\title{
Testimenetelmät uusien orgaanisten lannoitevalmisteiden lannoitusvaikutuksen määrittämiseen
}

\author{
Tapio Salo ${ }^{1)}$, Petri Kapuinen ${ }^{2)}$ ja Tiina Tontti ${ }^{3)}$ \\ ${ }^{1)}$ MTT Kasvintuotannon tutkimus, Planta, 31600 Jokioinen, tapio.salo@mtt.fi \\ ${ }^{2)}$ MTT Kasvintuotannon tutkimus, Toivonlinnantie 518,21500 Piikkiö, petri.kapuinen@mtt.fi \\ ${ }^{3)}$ MTT Kasvintuotannon tutkimus, Lönnrotinkatu 3, 50100 Mikkeli, tiina.tontti@mtt.fi
}

Lannoitevalmisteita koskeva lainsäädäntö uudistui vuonna 2006 voimaan tulleen lannoitevalmistelain myötä. Syyskuusta 2011 lähtien on voimassa lannoitevalmistelain nojalla annettu päivitetty MMM:n asetus 24/11. Lain voimaantulon jälkeen toimintaympäristön muutokset ovat kiihtyneet, ja lannoitevalmisteiden markkinoille saattamiseen ja valvontaan kohdistuu uusia vaateita. Perinteisten väkilannoitteiden hintavaihtelut ovat lisänneet mielenkiintoa ja tarjontaa uusiin lannoitevalmisteisiin, joiden kirjo vaihtelee aikaisemminkin käytetyistä orgaanisista lannoitevalmisteista (kompostit, mädätteet, puhdistamolietteet jne.) innovatiivisiin mikrobipreparaatteihin.

Tutkimuksen tavoitteena on tuottaa MMM:n ja Eviran käyttöön testausmalli uusia markkinoille tarjottavia orgaanisia lannoitevalmisteita varten. Lannoitevalmisteista testataan ensisijaisesti tuotteen ravinteiden (typpi ja fosfori) käyttökelpoisuus viljelykasveille ja vaikutukset kasvien kasvun edistymiseen. Hankkeessa kehitettävä työkalu antaa valvontaviranomaiselle (Evira ja MMM) välineen uusien tuotteiden hyväksymismenettelyyn. Myös viljelijät ja tuotteiden markkinoijat sekä valmistajat voivat hyödyntää orgaanisista lannoitevalmisteista tuotettua tietoa omassa päätöksenteossaan. Tässä tutkimuksen osassa arvioidaan ravinteiden käyttökelpoisuuteen liittyviä testausmenetelmiä.

Ravinteiden käyttökelpoisuuden osalta epäorgaanisen typen määritys on suhteellisen selkeää ja yksiselitteistä. Orgaanisen typen käyttökelpoisuus sitä vastoin on hankalammin arvioitavissa ja vapautuminen riippuu myös maassa vallitsevista olosuhteista. Erilaisilla uutoilla voidaan määrittää lannoitevalmisteen sisältämä liukoinen orgaaninen typpi ja suodattaa siitä eri kokoluokkaa olevat yhdisteet. Tämän liukoisen orgaanisen typen pitoisuuden määritys suhteessa epäorgaaniseen typpeen antaakin lisätietoa typen käyttökelpoisuudesta. Riittävän tarkan käsityksen saamiseksi typen käyttökelpoisuudesta tarvitaan kuitenkin typen mineralisaation mittaus, johon soveltuu esimerkiksi ISO 14238-standardin (2011) mukainen määritys. Tutkittavaa lannoitevalmistetta sekoitetaan sopivaan maahan, ja verrataan lannoitevalmisteesta vapautuvaa epäorgaanisen typen pitoisuutta pelkän maan typen vapautumiseen. Näytteistä analysoidaan maan epäorgaanisen typen pitoisuudet vähintään kahden ja neljän viikon kohdalla.

Fosforin käyttökelpoisuuden arvioinnissa Hedleyn fraktiointi antaa useimmilla lannoitevalmisteilla luotettavan kuvan fosforin käyttökelpoisuudesta. Veteen ja natriumbikarbonaattiin uuttuvaa osaa fosforista pidetään kasville käyttökelpoisena. Mikäli lannoitevalmisteen $\mathrm{pH}$ kuitenkin poikkeaa neutraalilta alueelta selvästi emäksiseksi, lannoitevalmisteen muhittaminen happaman maan kanssa, ja fosforipitoisuuden muutosten seuraaminen näyttäisi olevan tarpeellista.

Fosforin ja typen liukoisuutta tai käyttökelpoisuutta osoittamaan näyttää olevan mahdollista löytää suhteellisen yksinkertaisia analyysimenetelmiä ja nopeahkoja muhitusmenetelmiä.

\section{Asiasanat}

lannoitevalmiste, epäorgaaninen typpi, orgaaninen typpi, inkubointi, kokonaisfosfori, Hedleyn fraktiointi, lannoitusvaikutus 


\section{Johdanto}

Orgaaniset lannoitteet, orgaaniset maanparannusaineet ja kasvien kasvua edistävät aineet ovat maatalouden satokasvien potentiaalisia ravinnelähteitä ja kasvun tehostajia. Kiinnostus näitä orgaanisia lannoitevalmisteita kohtaan on lisääntynyt viimeaikaisten lannoitehintojen ja sadon myyntituoton voimakkaiden vaihteluiden vuoksi. Lannoitevalmistelaki (539/2006) edellyttää että markkinoidakseen lannoitevalmistetta sen tuottajan täytyy esittää mm. käytetyt raaka-aineet ja niiden alkuperä, kemiallinen ja biologinen koostumus sekä fysikaaliset ominaisuudet. Uuden orgaanisen lannoitevalmisteen tuottajan tulee myös määrittää tuotteen suositellut käyttömäärät ja turvalliset käyttötavat.

Tämän tutkimuksen tarkoituksena on arvioida kahta laboratoriomenetelmää orgaanisen typen ja fosforin käyttökelpoisuuden märittämisessä. Nopeita ja luotettavia laboratoriomenetelmiä tarvitaan uusien orgaanisten lannoitevalmisteiden käyttösuositusten määrittämiseen.

\section{Aineisto ja menetelmät}

Orgaaniset lannoitevalmisteet kerättiin useista meneillään olevista hankkeista. Typen mineralisaatio määritettiin inkubaatiotestillä aiemmissa tutkimuksissa käytetyn kasviaineksen typen mineralisaation määritysmenetelmän mukaisesti (Jensen ym. 2005). Inkubaatiotestissä testattavaa lannoitevalmistetta muhitettiin hietamaan kanssa (1-3 g lannoitevalmistetta, $50 \mathrm{~g}$ maata) lämpötilassa $15^{\circ} \mathrm{C}$. Maanäytteet otettiin $0,4,11$, 22, 42, 81, 168 ja 217 päivää muhituksen aloittamisen jälkeen. Maanäytteet uutettiin $(2 \mathrm{M} \mathrm{KCl})$ ja niistä analysoitiin ammonium- ja nitraatti-N (Lachat-autoanalysaattori). Jokainen lannoitevalmiste testattiin kolmena toistona. Lannoitevalmistetta sisältävien maanäytteiden epäorgaanisen typen pitoisuuksia verrattiin ilman lannoiteaineita muhitetun maan pitoisuuksiin. Fosforin käyttökelpoisuuden määritys perustui modifioituun Hedleyn fraktiointiin (Sharpley \& Moyer 2000). Fraktioinnissa lannoitevalmisteille tehtiin peräkkäiset uutot veden, $\mathrm{NaHCO}_{3}: \mathrm{n}$ (natriumbikarbonaatti eli ruokasooda, 0,5 M), $\mathrm{NaOH}: n$ (lipeä, $0,1 \mathrm{M}$ ) ja $\mathrm{HCl}: \mathrm{n}$ (suolahappo, $1 \mathrm{M}$ ) kanssa uuttosuhteella 1:60.

\section{Tulokset ja tulosten tarkastelu}

\section{Typen mineralisaatiotestit}

Typen mineralisaation testit osoittavat mineralisoituuko lannoitevalmisteen hajaantuessa siitä typpeä vai immobilisoivatko hajoamistuotteet maassa olevaa epäorgaanista typpeä (Kuva 1). Muhituksen alussa typpilannoitusvaikutus riippuu lannoitevalmisteen sisältämästä epäorgaanisen typen määrästä. Tilanne on sama sekä laboratoriossa että pelto-olosuhteissa. Mädätetty sianliete ja mädätetty puhdistamoliete sisälsivät muhituksen alussa suuren määrän epäorgaanista typpeä. Muhituksen edetessä mädätetyn sianlietteen hajoaminen alensi maan epäorgaanisen typen pitoisuuksia (Kuva 1). Muhitetuista orgaanisista lannoitevalmisteista voimakkaimman typen mineralisaation aiheutti meijerin jätevesilietteeseen pohjautuva kuivarae. Sekä kompostoidun että mädätetyn puhdistamolietteen vaikutuksesta epäorgaanisen typen pitoisuus pysyi tasaisena koko muhitusjakson ajan.

Pitkäaikaista maaperän muhitusta pidetään vakiomenetelmänä maan mineralisaatiopotentiaalin määrittämisessä (esim. St Luce ym. 2011). Todennäköisesti se antaa varsin hyvän arvion orgaanisen lannoitevalmisteen vaikutuksesta maassa saatavilla olevan typen määrään. Maan muhitusta voidaan tehdä erilaisilla menettelyillä, vaihdellen esimerkiksi lämpötilan ja kosteuden mukaan. Tässä esitettyä mineralisaatiotestiä nopeampi menetelmä on ISO-standardi 14238 (ISO 2011), jossa lannoitevalmistetta sekoitetaan kontrollimaahan ja muhitetaan $20{ }^{\circ} \mathrm{C}$ lämpötilassa. Epäorgaanisen typen pitoisuudet määritetään vähintään 2 ja 4 viikon kuluttua. Lannoitevalmisteen vaikutusta maan epäorgaanisen typen pitoisuuksiin verrataan vertailumaan vastaaviin pitoisuuksiin.

Muhitustestien ongelmia ovat niiden kalleus, ne vievät paljon aikaa ja vaativat paljon työaikaa. Yksinkertaisemmat kemialliset määritykset puolestaan selittävät typen mineralisaatiota varsin heikosti (Ros ym. 2011). Muhitus ISO-standardiin perustuen ja 4 viikon kestoisena voi kuvata lannoitevalmisteiden typen mineralisaatiopotentiaalin luotettavasti. Myös näissä kokeissa epäorgaanisen typen tasot vakiintuivat 22 vrk:n näytteenottoon mennessä. Lannoitevalmisteiden sujuvan testauksen ja käyttöohjeiden laadinnan kannalta nopea ja luotettava muhitustapa on eduksi. 


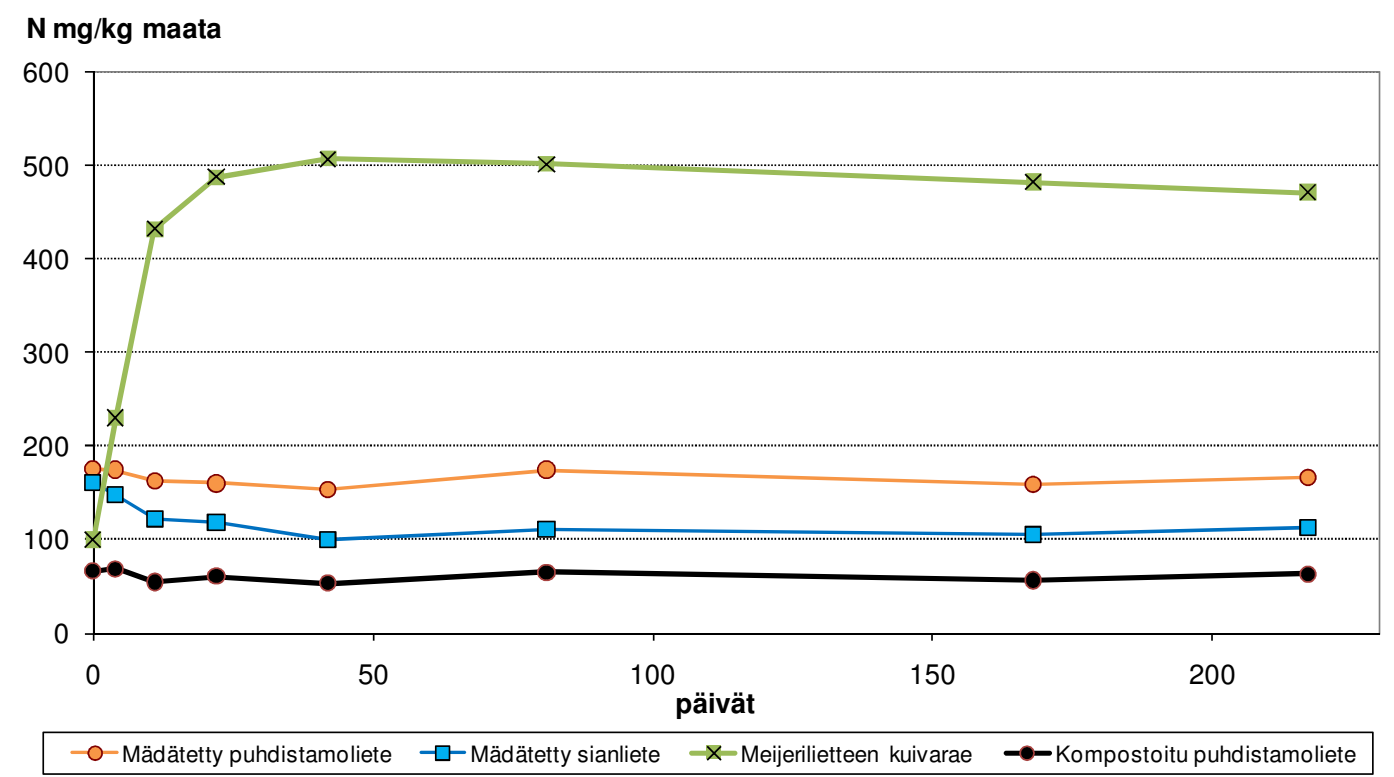

Kuva 1. Maan epäorgaanisen typen pitoisuudet neljän orgaanisen lannoitevalmisteen muhituksessa.

\section{Fosforin fraktiointi}

Veteen ja natriumbikarbonaattiin $\left(\mathrm{NaHCO}_{3}\right)$ liukeneva fosfori vallitsivat eläinlantaan perustuvien näytteiden Hedleyn fraktioinnissa (Kuva 2). Vesiliukoisten tulosten poikkeava arvo oli peräisin biokaasuprosessissa mädätetyn sianlietteen nesteosasta, jossa korkea fosforin liukoisuus on odotettavissa. Puhdistamolietteeseen pohjautuvien orgaanisten lannoitevalmisteiden fosforin liukoisuus oli yleensä hyvin alhainen. Siten niiden fosforista suurin osa oli lipeään $(\mathrm{NaOH})$ tai suolahappoon $(\mathrm{HCl})$ liukenevassa osassa (Kuva 3). Vesiliukoisten tulosten poikkeava arvo oli peräisin kompostoidun biojätteen näytteestä. Lipeään ja suolahappoon liukoisten tulosten poikkeavat arvot olivat peräisin kalkkistabiloiduista puhdistamolietenäytteistä.

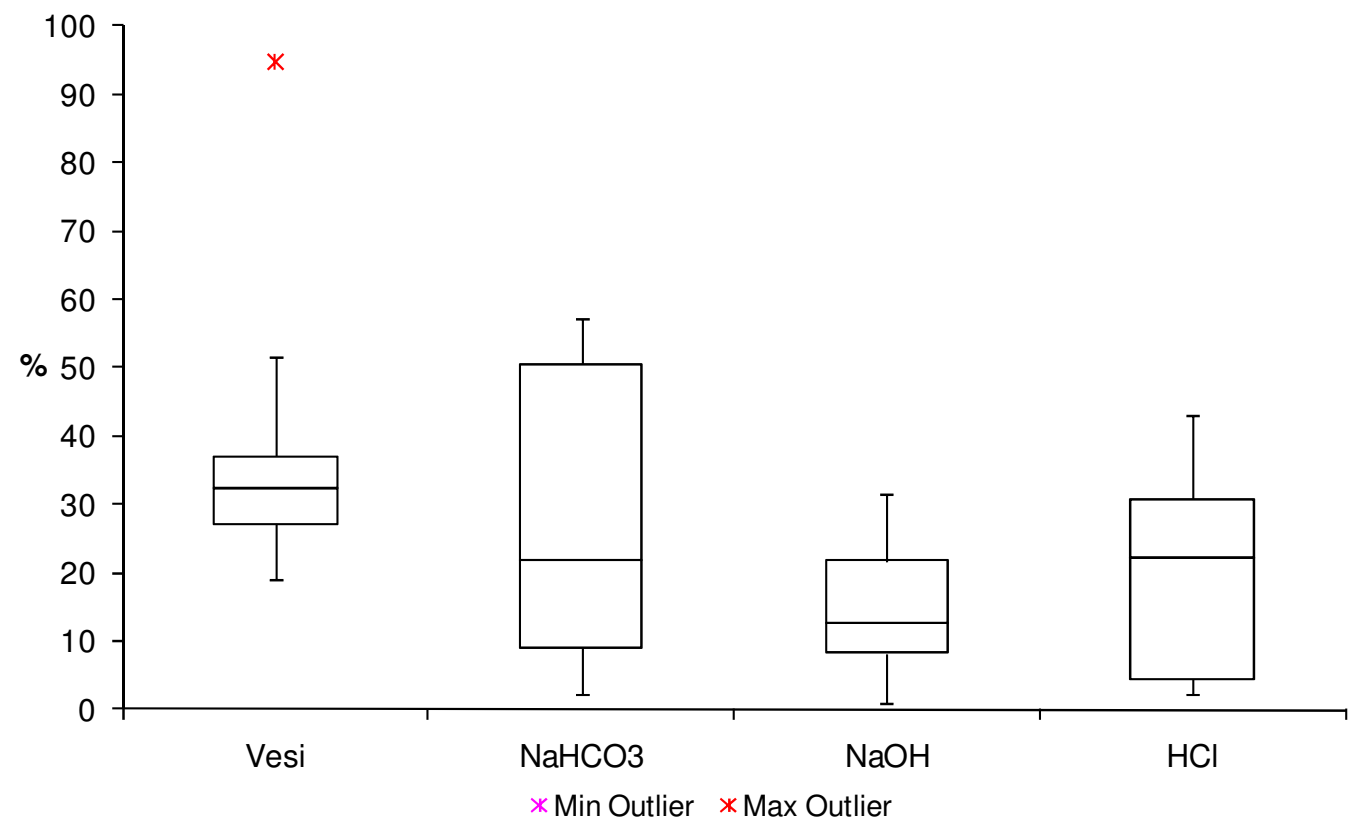

Kuva 2. Box-plot-jakaumat kokonaisfosforin Hedleyn fraktioista (\% kokonaisfosforista) biokaasuprosessissa mädätetyissä naudan ja sian lietelantanäytteissä $(n=12)$. Suurin poikkeava arvo (Max Outlier) esitetään kuvaajassa punaisella tähtimerkillä. 


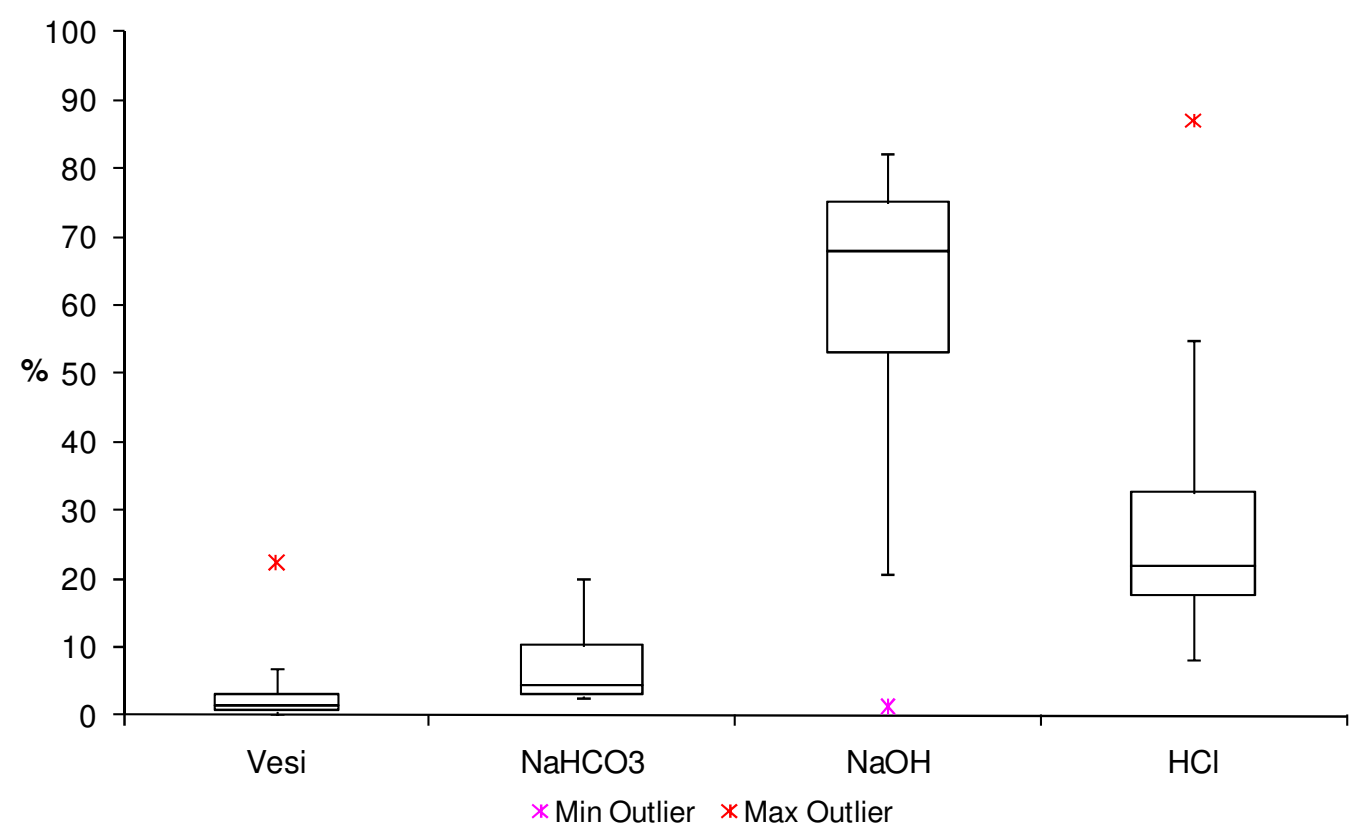

Kuva 3. Box-plot-jakaumat kokonaisfosforin Hedleyn fraktioista (\% kokonaisfosforista) yhdyskuntajätteeseen pohjautuvissa lannoitevalmistenäytteissä $(n=24)$. Suurimmat ja pienimmät poikkeavat arvot (Min/Max Outlier) esitetään kuvaajassa tähtimerkeillä.

Useissa aiemmissa tutkimuksissa on esitetty tuloksia orgaanisten lannoitevalmisteiden fosforin liukoisuuden määrittämisestä Hedleyn fraktioinnilla (esim. Huang et al. 2008, He et al. 2010). Toor ym. (2006) totesivat että on taloudellista ja suhteellisen helppoa analysoida suuri määrä jätenäytteitä Hedleyn fraktioinnilla verrattuna kalliimpiin ja aikaa vieviin tekniikoihin (esim. NMR, nuclear magnetic resonance). Veteen ja natriumbikarbonaattiin uuttuvaa osaa fosforista pidetään kasville käyttökelpoisena. Mikäli lannoitevalmisteen pH kuitenkin poikkeaa neutraalilta alueelta selvästi emäksiseksi, lannoitevalmisteen muhittaminen happaman maan kanssa, ja fosforipitoisuuden muutosten seuraaminen näyttäisi olevan tarpeellista.

\section{Johtopäätökset}

Typen mineralisaation muhitustestit ja Hedleyn fraktiointi antavat lupaavia arvioita orgaanisten lannoitevalmisteiden sisältämän orgaanisen typen ja kokonaisfosforin käyttökelpoisuudesta. Näitä ehdotettuja menetelmiä voidaan myös hyödyntää kansallisen ympäristötukiohjelman kehittämisessä. Myös orgaanisten lannoitevalmisteiden tuottajat ja käyttäjät voivat hyötyä näiden menetelmien käyttöönotosta. Nopea ja luotettava orgaanisten lannoitevalmistetuotteiden testaustapa tehostaa toimintaa kaikkien toimijoiden kannalta.

\section{Kirjallisuus}

He, Z., Zhang, H., Toor, G.S., Dou, Z., Honeycutt, C.W., Haggard, B.E. \& Reite, M.S. 2010. Phosphorus distribution in sequentially extracted fractions of biosolids, poultry litter, and granulated products. Soil Science, 175: 154161.

Huang, X-L., Chen, Y. \& Shenker, M. 2008. Chemical fractionation of phosphorus in stabilized biosolids. Journal of Environmental Quality 37: 1949-1958.

Jensen, L.S., Salo, T., Palmason, F., Breland, T.A., Henriksen, T.M., Stenberg, B., Pedersen, A., Lundström C. \& Esala, M. 2005. Influence of biochemical quality on C and N mineralisation from a broad variety of plant materials in soil. Plant and Soil 273: 307-326.

Lannoitevalmistelaki 539/2006. Naantali 29.6.2006.

MMM 2011. Maa- ja metsätalousministeriön asetus lannoitevalmisteista 24: 1 - 6 + 4 liitettä. Helsinki 1.9.2011. 
Ros, G.H., Temminghoff, E.J.H. \& Hoffland, E. 2011. Nitrogen mineralization: a review and meta-analysis of the predictive value of soil tests. European Journal of Soil Science 62: 162-173.

Sharpley, A.N. \& Moyer, B. 2000. Phosphorus forms in manure and compost and their release during simulated rainfall. Journal of Environmental Quality 29: 1462-1469.

St. Luce, M., Whalen, J.K., Ziadi, N. \& Zebarth, B.J. 2011. Nitrogen dynamics and indices to predict soil nitrogen supply in humid temperates soils. Advances in Agronomy 112: 52-102.

Toor, G.S., Hunger, S., Peak, J.D., Sims, J.T. \& Sparks, D.L. 2006. Advances in the characterization of phosphorus in organic wastes: environmental and agronomic applications. Advances in Agronomy 89: 1-72. 